\title{
The Lived Experience of Work and Career among Individuals with Bipolar Disorder: A Phenomenological Study of Discussion Forum Narratives
}

Susan Rathbun-Grubb, University of South Carolina, USA

\begin{abstract}
Individuals with invisible chronic illnesses are often at a disadvantage in the workplace in terms of job security, promotion, and occupational success. Because little is known about the use of public online support forums to help patients with mental health disorders cope with the impact their illness has on their work and career, this research identifies and examines online forum posts related to employment by contributors with bipolar disorder. Seven percent of the total eligible posts from four discussion forums $(n=7,712)$ contained mentions of work and career ( $n$ $=572$ ). A thematic analysis of the 572 posts is reported, organized by characteristics of contributors related to work and career histories, symptoms of bipolar disorder at work, needs for coping at work, the importance of work as part of a healthy life, disclosure of the illness, and recommendations by other contributors. The symptoms associated with the illness can have a negative impact in the work environment. Fear of stigma and other negative consequences inhibit workers from disclosing their condition and negotiating ways to get the fundamental accommodations they need. The posts reveal a climate of fear and uncertainty surrounding mental illness in the workplace, as well as individuals' desire to conquer their health challenges to achieve meaning and fulfillment in their work life.
\end{abstract}

Keywords: bipolar disorder; health justice; mental illness and work; online support forums; stigma

Publication Type: research article

\section{Introduction}

ndividuals with invisible chronic illnesses are often at a disadvantage in the workplace in terms of job security, promotion, and occupational success. An environment of health justice would enable those who can and want to work to do so, and would require a workplace that is supportive, makes reasonable accommodations, and is free of stigma-based discrimination (Tremblay, 2011). Because little is known about the use of public online support forums to help patients with mental health disorders cope with the impact their illness has on their work and career, this research identifies and examines online forum posts related to employment by contributors with bipolar disorder (BD). This exploratory research builds on previous research streams that have investigated self-disclosure, information seeking behaviors, and sharing behaviors among contributors to online mental health forums (Barney, Griffiths, \& Banfield, 2011; Bauer, Bauer, Spiessl, \& Kagerbauer, 2013; Giles \& Newbold, 2013; Horgan \& Sweeney,

The International Journal of Information, Diversity, \& Inclusion, 3(4), 2019

ISSN 2574-3430, jps.library.utoronto.ca/index.php/ijidi/index

DOI: $10.33137 /$ ijidi.v3i4.33011 
2010; Horgan, McCarthy, \& Sweeney, 2013; Savolainen, 2011; Schotanus-Dijkstra et al., 2014). This study attempts to answer the following research questions:

RQ1. To what extent do contributors to online forums for BD use the platform to discuss employment issues?

RQ2. What topics related to employment are discussed?

RQ3. What is the nature of the responses of contributors to questions and solicitations for support regarding employment?

The results of this research fill a void in what is known about the ways that people who suffer from BD manage the effect that their illness has on their work lives using public online forums; further, the findings reveal the nature of conversation about work in online support forums and the use of the forum as a safe space to discuss employment issues. This article begins with a literature review that defines health justice, provides an overview of research on BD and employment and stigma, and explores the use of online support forums. A summary of the methods employed in this study follows the review, and a discussion of findings and conclusions complete the report.

\section{Literature Review}

\section{The Capability Approach to Work and Health Justice}

The "freedom-based capability approach" proposed by Amartya Sen (2009) suggests that we assess justice and injustice as a consequence of an individual's capability to do the things he or she values. Of his philosophical framework, Sen asserts:

The focus here is on the freedom that a person actually has to do this or be that - things that he or she may value doing or being. Obviously, the things we value most are particularly important for us to be able to achieve. But the idea of freedom also respects our being free to determine what we want, what we value and ultimately what we decide to choose. (pp. 231-232)

Sen's capability approach has been extended to numerous areas of study, and two such areas are health and work. Philosopher Sridhar Venkatapuram (2011) defines health justice as the fundamental human right to the capability to be healthy. Venkatapuram, Ventriglio, and Bhugra (2015) state, "Every human being has a moral entitlement to a capability to be healthy, especially to a level which is commensurate with equal human dignity in the contemporary world. ... Health should not be seen as a mere absence of disease or illness, but as an ability to achieve a certain set of vital goals" (p. 518). Venkatapuram's view is pragmatic, as he posits that "human well-being is best conceptualized in terms of what the individual can actually be and do in their daily context" (Venkatapuram, 2014). An additional benefit of the capabilities approach to mental health is the potential it has to turn the focus from illness to health, thereby lessening the stigma associated with mental illness (Venkatapuram et al., 2015). By adopting a capabilities viewpoint, health care professionals are better positioned to help patients accept and navigate their diagnosis; patients are empowered with notions of freedom, choice, and values, as opposed to illness, barriers, and deficits, and may be less likely to internalize and validate any stigma they confront.

The International Journal of Information, Diversity, \& Inclusion, 3(4), 2019

ISSN 2574-3430, jps.library.utoronto.ca/index.php/ijidi/index

DOI: $10.33137 /$ ijidi.v3i4.33011 
Van der Klink et al. (2016) have applied the capability approach to work. Their definition of sustainable employability states:

Throughout their working lives, workers can achieve tangible opportunities in the form of a set of capabilities. They also enjoy the necessary conditions that allow them to make a valuable contribution through their work, now and in the future, while safeguarding their health and welfare. This requires, on the one hand, a work context that facilitates this for them and on the other, the attitude and motivation to exploit these opportunities. (p. 74)

This definition recognizes the role that the work environment plays in sustainable employability.

The intersection of work and health capabilities, sustainable employability, and the pursuit of health justice in the workplace form the framework of this research. For many, the capability to work and support oneself is central to one's sense of a healthy self, and according to research, is a way to achieve "societal and personal goals and values," including health and employment goals (Van der Klink et al., 2016, p. 72). Fulfillment of the capability and desire to work, regardless of mental health status, exemplifies health justice in the context of this study. The ability to earn a living and fully participate in the social and economic spheres to the extent that the individual is capable and desires to do so are two of the values, opportunities, or goals referred to by Sen (2009), Venkatapuram (2011; 2014), and Van der Klink et al. (2016).

Despite its public environment, the online forum is a place where many contributors share their innermost thoughts, their dreams and goals, as well as their perceptions of their capabilities, constraints, and freedom in the sphere of work. The forum is a rich source for reflection and revelation. It is also a place where information and ideas are exchanged between those who face similar barriers in terms of illness. By examining online support forum posts related to work and career, we can determine the ways in which individuals with bipolar disorder are articulating their capabilities and desires regarding work, pursuing their employment goals, and dealing with the challenges that could thwart their attempts to work or derive satisfaction from their work life.

\section{Bipolar Disorder and Employment}

$\mathrm{BD}$ is a psychiatric condition characterized by an instability of mood-cycling episodes of mania, hypomania, and depression-that results in impaired "work and social functioning" (American Psychiatric Association, 2013). Kessler et al. (2006) estimate that $5 \%$ of the general population has a disorder on the bipolar spectrum. BD is associated with significant personal and societal economic losses; it is estimated that there are 96.2 million lost work days and \$14.1 billion in lost productivity annually in the U.S. attributed to BD (Davidson et al., 2016; Kessler et al., 2006). Bowden (2005) states that only 30 to $60 \%$ of BD patients fully recover social and occupational functioning, even when symptom-free.

Research has shown that people who experience the depression and cognitive dysfunction associated with BD are more likely to have lower job satisfaction, more issues with absenteeism, and lower work quality (O'Donnell et al., 2017). BD and associated cognitive problems are also linked to instability in employment (Gilbert \& Marwaha, 2013; Marwaha, Durrani, \& Singh, 2013). Unemployed veterans with $\mathrm{BD}$ have greater neurocognitive impairment than those who are employed, and there is also an association between unemployment and the number of their

The International Journal of Information, Diversity, \& Inclusion, 3(4), 2019

ISSN 2574-3430, jps.library.utoronto.ca/index.php/ijidi/index

DOI: $10.33137 /$ ijidi.v3i4.33011 
hospitalizations and prescribed medications (Altshuler et al., 2007). Self-assessed cognitive impairment is a significant predictor of an unstable employment trajectory (Gilbert et al., 2010).

Attendance issues, conflict, and subpar performance at work are attributed primarily to the depressive symptoms of BD (O'Donnell, 2017; Simon, Ludman, Unützer, Operskalski, \& Bauer, 2008). Other cognitive impairments related to attention and verbal memory deficits stem from chronic depression (Boland et al., 2015). Any lessening of depressive symptoms is associated with positive work outcomes (Ryan et al., 2015). Occupational dysfunction and work disability are some of the most significant impairments caused by BD (Boland et al., 2015; Karpov et al., 2017; O'Donnell et al., 2017) and underlie many patients' experience of stigma (Nilsson, Kugathasan, \& Straarup, 2016).

\section{Bipolar Disorder and Stigma}

External or public stigma is defined by Corrigan, Larson, and Rüsch (2009) as societal "stereotypes, prejudice, and discrimination," while self-stigma is the awareness, agreement with, internalization, and application of those prejudices or stereotypes to oneself (p. 75). BD patients may experience both external and self-stigma after diagnosis. Goldberg (2012) found that patients who faced a diagnosis of BD had very negative reactions, based on the perception that they were entering, or being seen as entering, a marginalized societal status of the mentally ill. In a study by Nilsson et al. (2016), more than half of the subjects with BD believed that their illness would result in work-related stigmatization. Similarly, Michalak, Yatham, Maxwell, Hale, and Lam's (2007) qualitative assessment of the work experiences of BD patients indicated that workplace stigmatization was a major concern, along with dealing with management of BD symptoms at work, inconsistent work histories, disclosure of illness, and interpersonal relationship issues on the job. Work absences and extended times of unemployment or underemployment fractured the appearance of a cohesive, consistent career identity over time, and BD sufferers perceived that workplace stigma had negatively impacted career advancement or led to job loss.

External and self-stigmatization are both associated with increased symptoms, decreased ability to function in social and occupational roles, and a reduction in social support networks (Hawke, Parikh, \& Michalak, 2013). Just as the severity of depressive symptoms predicts deficits in psychosocial functioning, self-stigmatization is also associated with poor functioning (Cerit, Filizer, Tural, \& Tufan, 2012). It is a vicious cycle in which the symptoms of depression exacerbate self-stigma and self-perceived functional deficits (Gilkes, Perich, \& Meade, 2018), which in turn can intensify the symptoms of BD when paired with the social anxiety brought on by external stigma (Levy, Tsoy, Brodt, Petrosyan, \& Malloy, 2015).

\section{Online Support Forums}

Previous research indicates that individuals with chronic conditions use online forums as part of a coping strategy-to engage in a welcoming environment to gain peer support, build relationships and community, ask questions, and find information to support decision-making related to their illness (Berry et al., 2017; Highton-Williamson, Priebe, \& Giacco, 2015; Rains, Peterson, \& Wright, 2015; Savolainen, 2011; Yao, Zheng, \& Fan, 2015). Yao et al. (2015) assert that online forums can also "help stigmatized patients build interpersonal trust and enhance their sense of belonging both with other patients and with the community" (p. 379).

The International Journal of Information, Diversity, \& Inclusion, 3(4), 2019

ISSN 2574-3430, jps.library.utoronto.ca/index.php/ijidi/index

DOI: $10.33137 /$ ijidi.v3i4.33011 
Online forums are an important source of information and social support for people suffering from mental illnesses. In a study of the use of discussion forums for information about depression, Barney et al. (2011) discovered that forum contributors have a variety of unmet information needs and use the forums to discuss issues of stigma and disclosure; treatment; medications; and ways of coping with the illness. Similarly, Savolainen (2011) found that depressed individuals use discussion forums to seek information, pose questions, and ask for opinions of fellow sufferers. A mental health support forum created as a therapeutic intervention for students with depression also showed that sharing in the online environment can provide sufferers with coping strategies, social support, and general information about the illness (Horgan et al., 2013).

The research literature on the online activity of people with $B D$ is characterized primarily by studies on professionally designed and moderated online interventions for illness management. These studies describe the design and evaluation of web-based educational programs through which patients learn more about their diagnosis and treatment options; work through therapeutic modules; and engage in moderated peer and therapist-led discussions or chats (Barnes, Harvey, Mitchell, Smith, \& Wilhelm, 2007; Poole, Simpson, \& Smith, 2012; Proudfoot et al., 2007). Lauder et al. (2015) determined that the MoodSwings online program, which had discussion boards for participants, showed positive patient outcomes such as reduction of symptoms and improved functioning. A systematic review of research on internet-based and mobile technologies designed for $\mathrm{BD}$ patients recognized the potential benefits of interactive psychoeducational programs (Gliddon, Barnes, Murray, \& Michalak, 2017). Most of these online interventions included communication resources such as chat rooms and forums where participants could communicate with each other and with therapists; however, most were platforms unavailable to the public. Participants in one study noted the low level of activity on the discussion forum, but were reticent to contribute because of being uncomfortable or not wanting to be one of only a few contributors (Poole et al., 2012).

Researchers concluded that peer support proved to be an important part of the success of some BD support programs. For example, Proudfoot et al. (2009; 2012) examined peer support and coaching in the context of BD educational programs by matching newly diagnosed patients with peers who could provide support via online communication. These dialogues were a rich opportunity for new patients to express concerns about stigma, medications, symptoms, and therapy. Simon et al. (2011) also found that peer coaching increased program engagement and retention.

Several studies have focused on public BD online support forum communication and participation. Bauer et al.'s (2017) international survey of BD patients revealed that only 12.8 percent of the 1,222 participants used online support forums, groups, or chats. The researchers pointed out that while users of support forums often find them to be beneficial, other research has indicated that users may utilize the forums to avoid social engagement (Lawlor \& Kirakowski, 2014). Highton-Williamson et al. (2015) conducted a systematic review of 11 studies on the usage of social networking among patients with psychosis, including bipolar disorder; they reported that the motivation to use social networking sites centers on meeting new people, reconnecting with others, and obtaining peer support. Vayreda and Antaki (2009) examined initial introductory posts and follow-up responses in a Spanish language BD support forum, concluding that new contributors introducing themselves were often met with unsolicited, but empathic, peer advice to seek professional help, take prescribed medications, and focus on self-care.

Analyses of mental health support forums generally point out broad themes and topics, but three

The International Journal of Information, Diversity, \& Inclusion, 3(4), 2019

ISSN 2574-3430, jps.library.utoronto.ca/index.php/ijidi/index

DOI: $10.33137 /$ ijidi.v3i4.33011 
particular studies mentioned the discussion topic of employment. Contributors to depression forums in research by Barney et al. (2011) revealed concern about cognitive dysfunction and other symptoms hurting their work performance, as well as fear of losing a job or the potential consequences of disclosing the illness. Bauer et al. (2013) conducted a granular thematic analysis of BD patients' posts on online forums, and it showed that participants used the forums primarily to connect with similar individuals to gain emotional support and to discuss diagnoses and symptoms, social relationships, medication, physician-patient relationships, and other life issues; vocational concerns appeared in $11 \%$ of the posts. A study of 13 contributors ( $n=127$ posts) in the private forum of an interactive psychoeducation online program identified employment to be the second most common theme, among others such as medication, social support, and coping strategies (Poole, Smith, \& Simpson, 2015). Participants discussed employment insecurity, workplace stigma, job frustrations, unemployment, boredom, self-esteem, and financial concerns. The present study breaks new ground by focusing solely on the topic of employment concerns among contributors to public BD forums.

\section{Methodology}

This research examines the ways in which people with BD use public online support forums to help them cope with the impact their illness has on their work and career. The aims of the study are to determine the extent to which they use the forums to discuss work and career issues, the topical nature of those posts, and the types of responses and support given by fellow contributors. The inclusion criteria for online support forums in this study were designated prior to searching for potential sites: forum sites must have sub-forums dedicated to $B D$, must be publicly available and not require registration, and must be keyword-searchable. A Google search using the terms "bipolar," "discussion," "board," and "forum" located 11 potential online support websites where contributors post about BD. Seven websites were eliminated from the study because they did not meet all of the inclusion criteria. The four remaining websites were selected for analysis. All four are moderated sites that have been online from 14 to 19 years, ranging in size from 50,000 to 190,000 members. The number of individual posts within the BD sub-forums of the sites range from 24,000 to 110,000 .

Because of the public nature of the forum posts, an Institutional Review Board review found the research to be exempt from human subject protocols. However, an effort was made to respect the privacy of the individual contributors by not collecting user names and by removing identifying information, such as workplace, from quotations to preserve anonymity.

Individual posts ( $\mathrm{n}=7,712$ in 1,725 discussion threads) in the BD forums of the four websites dated between July 1, 2017 and June 30, 2018 made up the body of eligible posts. Purposive sampling through keyword-searching was used to draw a sample for analysis, a strategy employed by other thematic analyses of forum posts (Sillence \& Mo, 2014). Ultimately, the four websites did not have search tools robust enough to both limit by date and search for the keywords reliably, so I collected all posts within the specified date range and then used the page search feature in the Google Chrome browser to locate posts that contained the desired keywords, including "job(s)," "boss," "career," and "able to work." These keywords were chosen to represent the broad concepts related to employment likely to appear in colloquial forum posts. "Able to work" was selected because the single term "work" was most often seen in conjunction with whether therapies or medications did or did not work; the phrase also allowed me to find the words "not able to work" and "unable to work." The use of these keywords enabled me to find posts that related to work issues, but analysis was not limited to phrases containing the

The International Journal of Information, Diversity, \& Inclusion, 3(4), 2019

ISSN 2574-3430, jps. library.utoronto.ca/index.php/ijidi/index

DOI: $10.33137 /$ ijidi.v3i4.33011 
keywords; entire posts were analyzed. I made no assumptions about the contributors' ability or desire to work.

Before analysis, I created a set of initial codes based on themes in the literature on BD and work, such as the desire or inability to work; absenteeism; the influence of mental illness on career progression; stigma; and failures or successes in the workplace. The initial codes were "ability/inability to work," "symptoms," "problems at work," "disclosure," and "stigma." Using these codes but also tracking new themes that emerged, I conducted a preliminary analysis of these work-related forum posts $(n=572)$ to determine which aspects of work experience were shared and discussed. This process of in vivo coding (Saldaña, 2014) of posts identified additional themes that reflected the contributors' authentic concerns about work and career. Through an iterative method, including writing memos about my coding and findings, a set of codes was finalized and applied through content analysis to the sample of posts (see appendix for final codes). Qualitative coding software was not used in the analytical process, and the coding was completed by one researcher. There was no intention through this exploratory qualitative research to generalize findings beyond these discussion forums and users; however, the results were consistent across the different forums and suggest transferability to other research on the intersection between mental health and work. People who contribute to mental health forums use the sites to share their concerns and struggles with health issues that impact their work, and they ask others with similar problems for recommendations on coping with and overcoming them. Mental health forums are a fruitful resource for researchers who are exploring the nature of these challenges and the discourse surrounding them.

\section{Results}

Seven percent $(n=572)$ of the total eligible posts contained mentions of work and career. Firstperson narratives made up the majority of posts, while posts from caregivers or relations about someone else were infrequent. It was rare that a post was solely about work; many posts contained incidental mentions of work in the context of someone's whole life or health story, and job concerns made up part of a longer list of issues or expressed fears. Based on an analysis of the coded posts, several overarching categories emerged to organize discussion: characteristics of contributors related to work and career histories; BD symptoms at work; needs for coping at work; the importance of work as part of a healthy life; disclosure of the illness; and recommendations by other contributors. Each category is described in the subsections below.

\section{Characteristics of Contributors}

Contributors tended to post about work concerns within the context of a larger narrative. They described work histories, often having just resigned from a job, lost a job, or started a new job. For example, one contributor wrote:

I am looking for another job now. Have a couple interviews lined up for next week. It is hard to lie to the hiring manager about why I have gaps in my employment. I just have to make something up.

Occasionally they sought advice about what to do about a job or simply encouragement with their circumstances. Many issues brought up mirror those of the general public: coping with difficult bosses; dealing with job stress and grinding schedules; hating the job; finding meaningful work; or not being able to get into a field of choice; however, a deeper analysis reveals a host

The International Journal of Information, Diversity, \& Inclusion, 3(4), 2019

ISSN 2574-3430, jps. library.utoronto.ca/index.php/ijidi/index

DOI: $10.33137 /$ ijidi.v3i4.33011 
of unique problems faced by workers with $\mathrm{BD}$, illustrated in the following observations about many of the contributors and trends in post topics.

Many contributors had moved from job to job, had gaps in employment, and/or experienced long-term unemployment. As one person expressed:

I would like to have a real job and career, I'm tired of shitty jobs for shitty pay... I do good when I work but once the winter comes around I'm paralyzed with depression. I've quit so many jobs without notice when this happens. How am I supposed to explain what I'm going through to an employer? Mental illness is so stigmatized that it's just not worth the extra trauma.

A few suffered financial insecurity. Most of those who were not employed were frustrated because they want to work but have been unable to secure employment or remain employed. One contributor wrote:

I do want very badly to return to work and work a full time job but I have no skills or degree ...I have to be realistic too. I cannot handle a job anyway. I miss being able to work though. I'm very isolated now. I miss being around people.

Another wanted to deal with illness-related debt:

While I was psychotic/manic I generated so much credit card debt and need to make money to pay it down... I wish I could go back to work today but my memory and concentration are terrible.

Depression caused some to miss job interviews. Others posted because they had recently started a new job and were struggling or wanted to leave a job and were feeling helpless. Some held menial jobs despite their education or abilities when healthy.

Some described showing up late for work or not showing up at all. Absences jeopardized their job or caused job loss. For example, one contributor wrote:

I lost a part time job with flexibility that I had held for years because I was in the hospital. Once the job got wind of my medical condition they pulled out all stops to fire me (for not being able to call or come to work for a day while I was in the psych ER). I have applied for similar jobs recently but have not been hired.

Sometimes they had a criminal record stemming from manic or psychotic episodes, and that, coupled with a lack of positive references, made obtaining new employment difficult. When returning to work after a hospitalization or long absence, they describe feeling pressured to go back to work before they were ready. One contributor noted, "I haven't been to work since last Thursday. My boss is pressuring me to return and she's being a royal **** and knows nothing of the situation." Some felt that they were coerced to quit because of their illness; others quit intentionally to focus on getting well. Leaving a job was often sudden, accompanied by an impulsive resignation or wordless walkout. A subsequent fight for government or insurance disability benefits was frequently mentioned as an uphill battle:

I was turned down the first time, and then after I got a disability lawyer to help me, I got approved on the appeal, at the reconsideration level...... The chances of approval

The International Journal of Information, Diversity, \& Inclusion, 3(4), 2019

ISSN 2574-3430, jps.library.utoronto.ca/index.php/ijidi/index

DOI: $10.33137 /$ ijidi.v3i4.33011 
are higher, in general, if you have an attorney or a representative to help you, but even if you have a lawyer, it's still no guarantee that you'll win. A diagnosis of something is not enough to get approved...... The diagnosed condition (or conditions) has to be so severe that it affects your ability to work at any job, even a minimum wage job.

Even somewhat stable work situations were fraught with uncertainty. For example, a move out of state for a promotion led to the loss of a social support structure. Contributors complained of starting new projects and making commitments when feeling well, but being unable to follow through when symptoms of depression or anxiety returned. Some described frequently changing career interests that became obsessions they later got bored with or frustrated about.

Emotions about work circumstances were varied and show some evidence of self-stigmatization. Several contributors confided that they had low self-esteem related to their work, education, and employment history, feeling that they had limited opportunities. For example, one person wrote, "I would like to try to go to work again because otherwise l'm just sitting around an empty house all day and getting more depressed. But I don't know if any job will hire me again." Others were embarrassed about having to be supported by a partner or family member. Shame and grief over past decisions, as well as feeling incompetent or like a failure, were common themes. One contributor wrote, "I had to quit school and I lost my part time job and my apartment when I had been in the state hospital for so long. I mean I feel like a walking piece of crap and nobody wants to help me (except you guys)." Posts contained numerous references to fear of losing a job and the accompanying health insurance coverage because of the symptoms of their illness. Others were frustrated by their diagnosis and the impact it could have on their work because of stigma. For example, one contributor shared:

I hate being bipolar. I am embarrassed by it and only a handful of people know of my diagnosis. Our society does not understand the illness either. I hear ignorant people referring to crazy or unstable people as being "bipolar." I told my best friend I was bipolar and that's the last time we spoke. Most people want to distance themselves from us... I would never tell anyone I work with that I am bipolar. It would destroy my career.

Another observed, "I hear people put down people with bipolar (my boss for example) without even knowing anything about the disorder. Has the word 'bipolar' become a catch-all name for 'crazy'? I think it has... Or someone thinks it just means you change your mind too much."

\section{BD Symptoms at Work}

Seasonal changes, job stress and toxic work environments triggered or exacerbated symptoms and episodes of mania or depression. Contributors navigated the perilous circumstances of too much or too little social contact; fast-paced, deadline-driven jobs; difficult shift work; changes in schedule; loud or shared office spaces; or long commutes. People who had been out of work feared that going back to the work setting would trigger symptoms, such as anxiety and panic attacks or a full relapse. One contributor wrote:

I would like some advice on how to deal [with going to a new job]. The last time I had a job, my anxiety was so bad I was throwing up in the morning before work. I've had jobs in the past that have given me horrible anxiety and unfortunately the worst of them have resulted in me leaving.

The International Journal of Information, Diversity, \& Inclusion, 3(4), 2019

ISSN 2574-3430, jps.library.utoronto.ca/index.php/ijidi/index

DOI: $10.33137 /$ ijidi.v3i4.33011 
Entrepreneurs and the self-employed stated that making their own work schedule was crucial to accommodating symptoms and episodes of mania or depression. Even those with manageable work settings alluded to the possibility of future challenges and loss because of symptoms.

Contributors described physical and mental symptoms stemming from rapid cycling or longerterm episodes of mania or depression. These included agitation, irritation, confusion, anxiety, panic attacks, inability to concentrate or focus, memory lapses, paranoia, crying, talking too much, working too quickly or slowly, lack of motivation, hyper- or lack of productivity, extreme risk-taking, hypersexuality, and emotional outbursts. A contributor remembered:

I wouldn't shut up and I was acting crazy at work and my boss told me to stop acting like that. My boss and coworkers expressed concern but at the time I thought they were just picking on me. [My boss] told me my behavior was not exactly good and to "tone it down", so I think others [are] able to notice it more than yourself.

Side effects of medicine used to treat $\mathrm{BD}$, such as dizziness, sleepiness, and tremors affected job performance. Disordered sleep led to falling asleep at work or missing full days of work. Contributors shared stories about how their symptoms led to office romances, disagreements with co-workers, mistakes, social anxiety, poor decision-making, broken commitments, and exhausting efforts to keep up the appearance of health and wellness. The inability to keep up with the demands of work, manage time, and follow through were additional themes in the posts. For example, one contributor wrote:

I find going to work when depressed is one of the hardest things ever. Just showering and getting clothes on is hard... then there's the driving part, the anxiety... and then there's just sitting there at your desk staring at your screen telling yourself to just tell them you're sick and go home, you can't do this.

According to contributors, the results of these symptoms are devastating to workplace success and worsen job stress, leading to a loss of self-confidence from internalized stigma. A contributor observed:

These types of experiences and episodes become your identity for awhile, you begin to wonder if you will ever feel like your "old self" again... and you cannot predict when you will stabilize and pull yourself back into normality again.

\section{Needs for Coping at Work}

Contributors expressed a variety of needs or preferences on the job that fit with managing a chronic condition. Some found jobs with flexible scheduling or a type of job that could accommodate irregular attendance; these types of jobs were mentioned as solutions to the issues of absenteeism and difficulty getting started in the morning. As one contributor wrote:

I would suggest temporary or high turnover jobs that you can give up quickly if you get an episode...I find seasonal work is best for me [and] temporary work is good since I am always at risk of having an episode and having to leave my long-term job.

Others revealed that they preferred freelance or contract work or self-employment and working from home as a way to cope with the unpredictably of the illness. One contributor described:

The International Journal of Information, Diversity, \& Inclusion, 3(4), 2019

ISSN 2574-3430, jps.library.utoronto.ca/index.php/ijidi/index

DOI: $10.33137 /$ ijidi.v3i4.33011 
I was luck[y] enough to set up my own business and this made things a little easier as I could work to my moods and didn't have to explain to anyone. My best jobs had flexible schedules or even working from home that I could manage to do even if I was in a bad mood... A high stress job is a recipe for disaster. [At my old job] I was essentially my own boss, and loved the work I did, and I was making so much money. I finally felt I was going someplace. Being my own boss and away from people the majority of the day helped too... It was the best job I ever had, it was the most independent I have ever been, and I wish I could have it all back.

Others talked about the importance of self-care, good sleep, and adherence to medication or therapeutic plans prescribed by doctors to stay on track at work. A common concern was the need for accommodations to attend therapy appointments or a later start time; however, there was the acknowledgement of the risks associated with disclosure when asking for accommodations. When unable to cope effectively at work, some disclosed the desire to acquire disability benefits in order to step away from the chaos and focus on recovery and illness management.

\section{The Importance of Work}

Contributors expressed the desire to work or longed for a time when work was part of their lives. One contributor wrote, "I wanna work so bad in the hopes that it cures me of all of this." Others felt gratitude for the ability to work. Many considered work to be an essential part of a healthy lifestyle and equated it with normalcy and wellness. A contributor noted that "the most important thing is working on a career if possible. I think working is crucial to mental health." One person pointed out that in modern culture we define ourselves by our work and are judged by our jobs and career success: "It is the first thing people often ask you 'What do you do?' People judge you by your career but it's not really fair or a real measure of a person."

While some preferred flexible scheduling, others mentioned the benefits of a structured schedule. Structure provided a therapeutic effect in boosting confidence and self-esteem and managing the illness. Having to interact with other people prevented self-isolating and encouraged accountability, giving them a greater purpose and a reason to get out of bed in the morning. Work was used as a distraction from the illness and related problems and led to feelings of accomplishment. Not being able to work was demoralizing, eroding confidence and precipitating depression, financial struggles, relationship problems, legal issues, and a general downward spiral. A contributor shared:

I have been out of work and on disability for over a year due to having a psychotic episode... I am scared to go back to work in the event that I think it will trigger another one. My sleep is all messed up from staying up late and sleeping all day and I'm worried that I won't be able to sleep when I go back. I also have been paranoid about leaving my apartment... For eight years I was fine and worked hard and even got an award at my previous job for outstanding performance. I really want to return to a great job opportunity with my old employer but I am scared out of my mind and just really want my old life back.

\section{Disclosure}

A primary concern of contributors was intentional or unintentional disclosure of the illness to

The International Journal of Information, Diversity, \& Inclusion, 3(4), 2019

ISSN 2574-3430, jps.library.utoronto.ca/index.php/ijidi/index

DOI: $10.33137 /$ ijidi.v3i4.33011 
coworkers or supervisors. A common question was, should I disclose my condition to receive accommodations at work or explain absences or behaviors? Contributors were afraid of being stigmatized, bullied, deemed undependable, or even fired by an unscrupulous supervisor; many responders indicated that they had experienced all these unfortunate consequences. One contributor commented:

I had a bad experience once, where I was a temp, and I told the manager... that I was bipolar and an episode was creeping up and I needed to go home because things were bad... and 1 hour after I got home the temp agency said not to come back, and that they had already packed my things up.

Another had a different type of challenge:

I work in a small office so everyone knows my business and the manager is the biggest gossiper. My diagnosis is known and I'm called the crazy one. I hate it, but what can I do. I get made fun of because of all the excuses l've used. But the office manager seems to be sympathetic at times. She always tells me not to let myself get crazy (which I hate), but has taken tasks away from me if I felt overwhelmed.

Many felt pressured to disclose because of lengthy absences or hospitalizations that required physician documentation. Some were retaliated against with extra duties or poor evaluations for being away from the job on leave, as one contributor described: "They are moving me around the company as punishment for taking leave." Others worried that disclosure could have devastating consequences on future job or career prospects. There was also some mention of disclosure via questions on job applications or pre-employment personality or psychological testing.

Reactions to the question of disclosure were mixed based on the varied experience of contributors. Some had received empathy and support from coworkers or supervisors upon revealing BD; for example, one contributor wrote: “I'm pretty fortunate to be among those who have gotten a positive response [after disclosure]. That said, if I ever change jobs, I'm not sure l'd make the same call." Others claimed disclosure resulted in stigma and eventual job loss, despite laws and regulations against it. Concern about potential stigma was the primary reason behind advice to not disclose. Some suggested that the worker talk about physical symptoms or an ambiguous chronic condition to avoid stigma. Regrettably, it was stated that the nonjudgmental empathy one receives for another kind of diagnosis was not assured for the population who suffers from BD. One contributor wrote:

Maybe if I had cancer they'd understand, since people with cancer seem to be celebrated these days. While those with mental health problems are basically told to just go away or better yet, be locked up.

Depending on the country, people with mental illness may have some legal protections in the workplace. In the U.S., for example, the Americans with Disabilities Act offers citizens the right to non-disclosure, privacy upon disclosure, and job accommodations such as more frequent breaks, a quieter work atmosphere, flexible scheduling, and task modifications, as long as these accommodations do not cause "undue hardship" for the employer (ADA National Network, 2017). The U.S. Family and Medical Leave Act prevents employers from retaliating against employees who take extended leave. With some exceptions, it provides citizens who work for qualifying

The International Journal of Information, Diversity, \& Inclusion, 3(4), 2019

ISSN 2574-3430, jps.library.utoronto.ca/index.php/ijidi/index

DOI: $10.33137 /$ ijidi.v3i4.33011 
employers with up to 12 weeks of unpaid leave during a 12-month period; the employer must place the returning employee in the same or nearly identical job upon return with the same pay and benefits (U.S. Department of Labor, 2015). If someone is not accommodated or experiences discrimination or job loss after disclosure or leave, he or she would have to pursue legal action against the employer-a daunting prospect for anyone. The implications of having legal protections are that employees have recourse when they are not allowed options for accommodating the effects of $\mathrm{BD}$ in the workplace. They also have the right to pursue governmental disability insurance benefits. Unfortunately, these options add yet another layer of challenges to work through when they are already constrained by their condition and all that illness management entails.

\section{Recommendations from Others}

Aside from universal encouragement and sharing of their own career stories, those who responded to each other's posts were willing to provide suggestions and advice in response to specific questions or general narratives about work. Specific questions ranged from what type of jobs to seek and the type of work others did, to the best ways to return to work after hospitalization or extended leave, whether and how to apply for government or insurance disability benefits, and how to cope with or hide symptoms on the job.

Some suggestions on the type of work to pursue focused on flexibility of scheduling and lower levels of job stress; additionally, encouragement was given to find the kind of job that fits one's strengths and accommodates the weaknesses brought on by the illness. Responders offered commiseration; support; and advice to seek out better medications or more effective therapy, alternative employment, and phased or part-time returns to work. Contributors were advised to focus on work as a therapeutic tool, and to make whatever modifications were possible in their current work environment, such as hours, duties, or location of work, such as telecommuting. Requesting a different supervisor was an additional suggestion. Others emphasized using the protections that accrue to employees through the aforementioned national laws and regulations. Another resource suggested was community or government agencies that help with reentry to the workforce.

The gist of many responses was to focus on self-care; become more self-aware; simplify one's work life; and know when a job is having a negative influence on one's health. As one person responded to questions about returning to work:

I would not return to work until I knew I could function within a group of strangers...I know you want your old life back; to feel like yourself again, but be kind to yourself by giving yourself all time you need. Get your sleep back into rhythm - Hard to do but things like exercise and proper diet will help. Maybe contact your boss and schedule a phased return or at least call in to the office / workplace for a few hours before going back. Don't worry what others think - There will be one or two lunkheads but the vast majority will be happy to see you as they will have missed you or will know of someone close to them who is going through this themselves. Be someway proud of your accomplishments - Some clever dude once said "It is not the achievements that a person should be judged, but the adversity that they have faced."

Another recommendation stated that the middle of an episode is not the best time to make big decisions about work. Generally, contributors shared empathic responses encouraging people to

The International Journal of Information, Diversity, \& Inclusion, 3(4), 2019

ISSN 2574-3430, jps. library.utoronto.ca/index.php/ijidi/index

DOI: $10.33137 /$ ijidi.v3i4.33011 
find work situations that bring health and help them achieve work-life balance. Sharing job stories appeared to help people find hope that they can overcome their current circumstances, and that it is possible to have BD and achieve job and career satisfaction.

\section{Discussion}

This study is unique in that it examines in depth the public BD forum post narratives related to employment and captures the detailed work concerns of forum contributors. It is one of few research projects that thematically analyze the content of forums dedicated to BD. The narratives explored in this research are consistent with the literature on BD symptoms and work described previously, and they illustrate that stigmatization by both self and others is a common experience. This consistency is important to note, however, because it illustrates that certain $\mathrm{BD}$ patients who are active in online communities are motivated to reach out for support and answers specific to their work challenges. The findings also demonstrate the willingness of knowledgeable peers to offer advice when solicited for ideas-a valuable resource for those who are not accessing traditional formal help or therapeutic services. The literature on BD interventions shows the efficacy of educational and support programs in the online environment. Given the overwhelming losses to worker productivity and effectiveness due to $\mathrm{BD}$, healthcare professionals should encourage patients to use online resources and prioritize individual modules or interventions focused on work and career issues that leverage peer and therapist support. Interventions can teach patients what to expect and how to cope with the impact the disorder may have on their careers. These interventions are normally reserved for recruited and registered individuals but could be adapted for a wider inclusion of participants worldwide.

In these public spaces, contributors are surprisingly candid about their work histories and their stories about how their illness and its symptoms affect their ability to work. Expressions of grief and anguish over past employment failures and dashed hopes over future prospects are laid bare. Raw feelings and truth-telling online resembles the type of discussions patients might have privately with a therapist or counselor. While this finding is not novel when examining online support forums, it is important to note that employment concerns are not just utilitarian in nature but are also associated with strong emotional states. The fact that patients turn to the forums to deal with work issues further illustrates the impact of BD on work and career and the need for therapeutic interventions targeted to those issues.

The forums are a rich source of data on stigma. Potential stigma in the workplace looms large in the mind of contributors who are contemplating disclosure of their illness to supervisors or coworkers. Their reticence is well-founded given the negative consequences experienced by responders. There is also evidence of self-stigmatization in the posts that describe self-doubt and low self-esteem in terms of work history and prospects. Consistent mentions of disability status and non-discriminatory accommodations in the workplace illustrate that many contributors are aware that legal protections exist, but it is unclear how they are utilizing them and whether they are seeking disability benefits from their government. The relationship between use of online support forums and the pursuit of legal protections or disability benefits would be another interesting area for further investigation.

\section{Conclusion}

This research answered the following exploratory research questions:

The International Journal of Information, Diversity, \& Inclusion, 3(4), 2019

ISSN 2574-3430, jps.library.utoronto.ca/index.php/ijidi/index

DOI: $10.33137 /$ ijidi.v3i4.33011 
RQ1. To what extent do contributors to online forums for BD use the platform to discuss employment issues?

RQ2. What topics related to employment are discussed?

$\mathrm{RQ3}$. What is the nature of the responses of contributors to questions and solicitations for support regarding employment?

Seven percent of the collected posts contained subject matter related to work and career. The wide variety of topics and the nature of responses to questions and solicitations for support were delineated, discussed, and situated herein in relation to what is already known about BD and work and participation in online support forums.

There are several limitations to this study. The English-language forum posts analyzed represent a tiny fraction of the online communication that is occurring on social media sites and the numerous online forums and communities worldwide. The small percentage of BD patients who are active online are not representative of the total population of patients, most of whom do not participate in public forums. This exploratory analysis is the work of a sole author and did not benefit from another researcher's interpretation and tests of interrater reliability. Nevertheless, the results do show that public online support forums are a place where people seek information about and address the intersection of BD and work. Revealed through questions, answers, and narratives in posts, the forums are a place for sharing, venting, and informationseeking. It is impossible to know from a study such as this what lurkers, who simply read posts but do not contribute to the forums, do with the information they gather. It is only minimally possible to track what contributors do with the information they obtain, as we're limited to what they divulge in their follow-up posts. This research focuses primarily on the topical coverage of posts and responses. Future studies that focus on the use of information about work obtained through online forums would be a valuable complement.

This investigation found that contributors to BD forums who discuss work issues value work as part of a healthful life, and they want to work and have career success. Unfortunately, the symptoms associated with the illness can have a negative impact in the work environment. Cognitive dysfunction, depression, agitation, brain fog, disordered sleep, and other symptoms wreak havoc on the sufferer's ability to get to and stay at work, be productive, and function effectively. Workers with BD find themselves in a no-win situation: fear of stigma and other negative consequences make them hesitant to disclose their condition, but not disclosing prevents them from negotiating ways to get the fundamental accommodations they need at work.

Respondents to contributor questions commiserate, provide empathy and advice for dealing with problems at work related to $\mathrm{BD}$, and share philosophical views on the relationship between work and wellness. These narratives reveal a climate of fear and uncertainty surrounding mental health in the workplace, as well as individuals' desire to conquer their health challenges to achieve meaning and fulfillment in their work life. Their stories about wanting to work despite health challenges resonate with Venkatapuram's (2011; 2014) and Van der Klink et al.'s (2016) capability approach to mental health and sustainable employability respectively, in that contributors share that they are striving to attain the vital goals they value in their daily context. People with BD have the freedom to pursue work situations that fit with their personal goals and capabilities, despite the health-related barriers they face; however, in an environment in which health justice is uncertain, the pursuit is fraught with risk.

The International Journal of Information, Diversity, \& Inclusion, 3(4), 2019

ISSN 2574-3430, jps.library.utoronto.ca/index.php/ijidi/index

DOI: $10.33137 /$ ijidi.v3i4.33011 
The work environment is a challenging place where sharing and disclosure can be dangerous. In contrast, online mental health forums are a safe space where contributors can ask questions and share challenges related to work and career, regardless of an individual's time zone, geographic location, or circumstance. In fact, the online sphere is a fruitful way to study mental health and provide health interventions on a global scale. The economic consequences of untreated or ineffectively treated BD are clearly international in scope; according to the World Health Organization (2011):

Untreated mental disorders [account] for 13 percent of the total global burden of disease. . . [and] the gap between the need for treatment for mental disorders and its provision is wide all over the world. For example, between $76 \%$ and $85 \%$ of people with severe mental disorders receive no treatment for their mental health problem in lowand middle-income countries; the corresponding range for high-income countries is also high: between $35 \%$ and $50 \%$ (p. 1).

The literature reviewed here represents international perspectives on $\mathrm{BD}$ and on the use of online support forums. International readers and researchers who are working on online interventions for BD can work cross-culturally to create, share, and support electronic and mobile health tools that can be replicated through translation. International efforts, such as those of Bauer et al.'s (2017) 17-country survey are laudable and should be built upon, in the effort to better understand the use of online support groups by BD patients. Discovering which type(s) of online resources will assist this population in reaching their work and career goals is a particular area of interest.

These research findings will add to the knowledge base on BD and work, as well as invisible illness more broadly and its effect on, or coexistence with, problems related to work and career mobility and progression. The results are important for several groups of people: patients who have BD; their co-workers and employers; and mental health professionals and educators. The lived experiences described herein reveal the challenges faced by those who struggle with BD and can help to bridge mutual understanding. The findings could be used to inform educational materials that destigmatize mental illness and promote the support of sensible accommodations for patients struggling with $\mathrm{BD}$ and other conditions that negatively impact work functioning.

\section{Appendix}

\section{Final Codebook}

\begin{tabular}{|c|c|c|}
\hline Code & Definition & Examples \\
\hline Accommodations & $\begin{array}{l}\text { The ways contributors } \\
\text { make and request } \\
\text { allowances or alternatives } \\
\text { in the workplace to } \\
\text { accommodate illness, } \\
\text { symptoms, or care; } \\
\text { whether and how } \\
\text { employers make } \\
\text { accommodations }\end{array}$ & $\begin{array}{l}\text { "At work they let me take an hour each } \\
\text { week for therapy plus travelling time and } \\
\text { also time to see my psych." } \\
\text { "the office manager seems to be } \\
\text { sympathetic at times. She ... has taken } \\
\text { tasks away from me if I felt } \\
\text { overwhelmed." }\end{array}$ \\
\hline
\end{tabular}

The International Journal of Information, Diversity, \& Inclusion, 3(4), 2019

ISSN 2574-3430, jps.library.utoronto.ca/index.php/ijidi/index

DOI: $10.33137 /$ ijidi.v3i4.33011 


\begin{tabular}{|c|c|c|}
\hline Code & Definition & Examples \\
\hline Coping mechanisms & $\begin{array}{l}\text { Ways contributors deal } \\
\text { with the effects their } \\
\text { illness has on their work }\end{array}$ & $\begin{array}{l}\text { "I've only been working a small number of } \\
\text { part-time hours to cope. I've found it } \\
\text { difficult to sustain employment, either } \\
\text { because of the bipolar symptoms or the } \\
\text { sedation from the meds I'm on." } \\
\text { “I work at [redacted], and sometimes my } \\
\text { job entails calling manufacturers. I usually } \\
\text { just leave sticky notes on the paperwork } \\
\text { with instructions for my boss to call them. } \\
\text { He knows 'I'm not good with people.' } \\
\text { Sometimes the tension comes out as } \\
\text { aggression; and he'd rather deal with it } \\
\text { than risk me ruining things. It's as close to } \\
\text { good as I could get." }\end{array}$ \\
\hline Disclosure & $\begin{array}{l}\text { Telling or planning to tell } \\
\text { employer or co-workers } \\
\text { about illness; } \\
\text { consequences of disclosure }\end{array}$ & $\begin{array}{l}\text { "I told my employer and it was actually } \\
\text { GOOD that I did! I had been having a } \\
\text { really rough go of it, and flaky and taking } \\
\text { off work and such, and I didn't want them } \\
\text { to think they'd just hired some flaky mess. } \\
\text { My boss has a degree in psychology so I } \\
\text { took a gamble, and explained the whole } \\
\text { story... we talked a while and he said if I } \\
\text { needed to like, leave an hour or two early } \\
\text { I could make up the time, etc." } \\
\text { "I lost a part time job with flexibility that } \\
\text { I had held for years because I was in the } \\
\text { hospital. Once the job got wind of my } \\
\text { medical condition they pulled out all stops } \\
\text { to fire me (for not being able to call or } \\
\text { come to work for a day while I was in the } \\
\text { psych ER). I have applied for similar jobs } \\
\text { recently, but have not been hired." }\end{array}$ \\
\hline \multirow[t]{2}{*}{ Disability/legal } & $\begin{array}{l}\text { Plans to or pursuit of } \\
\text { disability insurance } \\
\text { benefits; workplace laws or } \\
\text { regulations on breaks or } \\
\text { hours or those that protect } \\
\text { workers with disabilities }\end{array}$ & $\begin{array}{l}\text { "I changed many jobs. The best advice I } \\
\text { can give you is find a job that you like if } \\
\text { possible. People go on disability for having } \\
\text { anxiety... Waiting time is long but after I } \\
\text { burned out from work I went on welfare } \\
\text { until my disability app was approved." }\end{array}$ \\
\hline & & $\begin{array}{l}\text { "Are your benefits running out? (I don't } \\
\text { know how it works, even though I'm on } \\
\text { disability myself.) Canada and the U.S. }\end{array}$ \\
\hline
\end{tabular}

The International Journal of Information, Diversity, \& Inclusion, 3(4), 2019

ISSN 2574-3430, jps.library.utoronto.ca/index.php/ijidi/index

DOI: $10.33137 /$ ijidi.v3i4.33011 


\begin{tabular}{|c|c|c|}
\hline Code & Definition & Examples \\
\hline & & $\begin{array}{l}\text { may have very different approaches to it. } \\
\text { Can you extend your benefits? And how } \\
\text { soon is your old employer expecting your } \\
\text { return?" }\end{array}$ \\
\hline \multirow[t]{2}{*}{ Emotions and affect } & $\begin{array}{l}\text { How contributors feel } \\
\text { about work; desire, ability, } \\
\text { or inability to work; self- } \\
\text { stigma; positive or } \\
\text { negative self-esteem and } \\
\text { judgments }\end{array}$ & $\begin{array}{l}\text { "Ever since my Bipolar diagnosis, I never } \\
\text { realized how much I took emotions for } \\
\text { granted. I never thought I would lose the } \\
\text { ability to feel certain things. I didn't think } \\
\text { it was possible to lose emotions like you } \\
\text { would lose your keys or your wallet. I } \\
\text { don't feel motivated to get a job. At all. } \\
\text { It's like a switch went off in my brain and } \\
\text { apathy rules over all else. I can't seem to } \\
\text { care about career or academic goals. I } \\
\text { don't have dreams or aspirations } \\
\text { anymore." }\end{array}$ \\
\hline & & $\begin{array}{l}\text { "I'm feeling frustrated. Because I'm } \\
\text { unable to work efficiently during the } \\
\text { week, I'm stuck in the office on a Sunday, } \\
\text { with a partially-functioning brain." }\end{array}$ \\
\hline \multirow[t]{2}{*}{ Stigma } & $\begin{array}{l}\text { Stereotyping/prejudgment } \\
\text { based on illness by others }\end{array}$ & $\begin{array}{l}\text { "I hear people put down people with } \\
\text { bipolar (my boss for example) without } \\
\text { even knowing anything about the disorder. } \\
\text { Has the word 'bipolar' become a catch-all } \\
\text { name for "crazy'?" }\end{array}$ \\
\hline & & $\begin{array}{l}\text { "I told my best friend I was bipolar and } \\
\text { that's the last time we spoke. Most people } \\
\text { want to distance themselves from us." }\end{array}$ \\
\hline \multirow[t]{3}{*}{ Symptoms } & $\begin{array}{l}\text { Types of symptoms and the } \\
\text { effect and consequences of } \\
\text { depressive, manic, } \\
\text { hypomanic, or psychotic } \\
\text { symptoms on the ability to } \\
\text { work or function at work; } \\
\text { side effects of medications }\end{array}$ & $\begin{array}{l}\text { "My anxiety has gotten so bad that I can } \\
\text { barely tolerate walking to my desk } \\
\text { without having a panic attack in fear that } \\
\text { someone is staring at me or laughing at } \\
\text { me... It is almost physically painful to get } \\
\text { out of bed and going through the motions } \\
\text { of going to work." }\end{array}$ \\
\hline & & $\begin{array}{l}\text { "you attempt to rewire the building you } \\
\text { work in so piped in music will work. In } \\
\text { high heels, climbing on ladders and utility } \\
\text { sinks and having no idea how to even wire } \\
\text { your own tv." }\end{array}$ \\
\hline & & "I have struggled all my life in work \\
\hline
\end{tabular}

The International Journal of Information, Diversity, \& Inclusion, 3(4), 2019

ISSN 2574-3430, jps.library.utoronto.ca/index.php/ijidi/index

DOI: $10.33137 /$ ijidi.v3i4.33011 


\begin{tabular}{|c|c|c|}
\hline Code & Definition & Examples \\
\hline & & $\begin{array}{l}\text { situations, throwing myself at it one } \\
\text { min[ute] and giving it my all and then the } \\
\text { next day not even being able to } \\
\text { concentrate or be slightly motivated... I } \\
\text { have once again fallen into the same } \\
\text { difficulties, experiencing major panic } \\
\text { attacks now and the feeling of just } \\
\text { needing to get out. I love the job itself } \\
\text { but just feel like I can't cope at times and } \\
\text { everything I have to do, no matter how } \\
\text { simply is just a massive task." }\end{array}$ \\
\hline \multirow[t]{2}{*}{ Work environment } & $\begin{array}{l}\text { Types of jobs/settings; } \\
\text { supportive/ unsupportive } \\
\text { atmospheres or people; } \\
\text { triggers at work }\end{array}$ & $\begin{array}{l}\text { "For the most part I find my colleagues } \\
\text { supportive. I don't need to make excuses } \\
\text { when I need a few days off. Of course, I } \\
\text { can only achieve that supportive } \\
\text { environment thanks to my meds, and } \\
\text { working with good people." }\end{array}$ \\
\hline & & $\begin{array}{l}\text { "[My boss] didn't fire me. I think he knew } \\
\text { what was going on but has never said } \\
\text { anything about it... By year end, the roller } \\
\text { coaster was back at the top and I got my } \\
\text { rate increased to a little higher than it } \\
\text { had been before the fiasco... My boss has } \\
\text { let me know I am likely to be the person } \\
\text { who turns out the lights in a few years if I } \\
\text { don't screw it up. He is retiring soon and } \\
\text { has told me how I need to deal with the } \\
\text { person replacing him. He suggested I write } \\
\text { things down before phone calls so I use } \\
\text { complete sentences and cover all the } \\
\text { points I need to. Earlier I said I am almost } \\
\text { certain he knows; that might be an } \\
\text { understatement. I need to sit down with } \\
\text { him and thank him for all he has done for } \\
\text { me." }\end{array}$ \\
\hline Work history & $\begin{array}{l}\text { Descriptions/impact of } \\
\text { engagement with or } \\
\text { disengagement from work } \\
\text { over long term; } \\
\text { starting/quitting jobs; } \\
\text { looking for jobs; plans for } \\
\text { work; career dreams }\end{array}$ & $\begin{array}{l}\text { "Employment is difficult for me as } \\
\text { someone with bipolar. I've quit jobs } \\
\text { impulsively due to mania, paranoia, and } \\
\text { have lost jobs because of my symptoms } \\
\text { and not being able to show up." } \\
\text { "I haven't been able to keep a job in } 9 \\
\text { years. I graduated college and dreamed of }\end{array}$ \\
\hline
\end{tabular}

The International Journal of Information, Diversity, \& Inclusion, 3(4), 2019

ISSN 2574-3430, jps.library.utoronto.ca/index.php/ijidi/index

DOI: $10.33137 /$ ijidi.v3i4.33011 


Code Definition Examples

going to graduate school but the deaths of my parents and husband and [mental illness] got in the way. I lately tried to work an assembly job and couldn't do it. I still want a master's degree and I'm wondering if it's worth the debt when I can't work right now."

\section{References}

ADA National Network. (2017). Mental health conditions in the workplace and the ADA. Retrieved from https: //adata.org/factsheet/health

Altshuler, L., Tekell, J., Biswas, K., Kilbourne, A. M., Evans, D., Tang, D., \& Bauer, M. S. (2007). Executive function and employment status among veterans with bipolar disorder. Psychiatric Services, 58(11), 1441-1447. https://doi.org/10.1176/appi.ps.58.11.1441

American Psychiatric Association. (2013). Diagnostic and statistical manual of mental disorders (5th ed.). Arlington, VA: American Psychiatric Publishing.

Barnes, C., Harvey, R., Mitchell, P., Smith, M., \& Wilhelm, K. (2007). Evaluation of an online relapse prevention program for bipolar disorder: An overview of the aims and methodology of a randomized controlled trial. Disease Management \& Health Outcomes, 15(4), 215-224. https://doi.org/10.2165/00115677-200715040-00003

Barney, L. J., Griffiths, K. M., \& Banfield, M. A. (2011). Explicit and implicit information needs of people with depression: A qualitative investigation of problems reported on an online depression support forum. BMC Psychiatry, 11(88). https://doi.org/10.1186/1471-244X-11-88

Bauer, R., Bauer, M., Spiessl, H., \& Kagerbauer, T. (2013). Cyber-support: An analysis of online self-help forums (online self-help forums in bipolar disorder). Nordic Journal of Psychiatry, 67(3), 185-190. https://doi.org/10.3109/08039488.2012.700734

Bauer, R., Conell, J., Glenn, T., Alda, M., Ardau, R., Baune, B. T., . . Bauer, M. (2017). International multi-site survey on the use of online support groups in bipolar disorder. Nordic Journal of Psychiatry, 71(6), 473-476. https://doi.org/10.1080/08039488.2017.1334819

Berry, N., Lobban, F., Belousov, M., Emsley, R., Nenadic, G., \& Bucci, S. (2017). \#WhyWeTweetMH: Understanding why people use Twitter to discuss mental health problems. Journal of Medical Internet Research, 19(4), e107. Retrieved from https://doi.org/10.2196/jmir.6173

The International Journal of Information, Diversity, \& Inclusion, 3(4), 2019

ISSN 2574-3430, jps.library.utoronto.ca/index.php/ijidi/index

DOI: $10.33137 /$ ijidi.v3i4.33011 
Boland, E. M., Stange, J. P., Molz Adams, A., LaBelle, D. R., Ong, M.-L., Hamilton, J. L., . . . Alloy, L. B. (2015). Associations between sleep disturbance, cognitive functioning and work disability in bipolar disorder. Psychiatry Research, 230(2), 567-574. https://doi.org/10.1016/j.psychres.2015.09.051

Bowden, C. (2005). Bipolar disorder and work loss. American Journal of Managed Care, 11(3, sup.), S91-S94.

Cerit, C., Filizer, A., Tural, Ü., \& Tufan, A. E. (2012). Stigma: A core factor on predicting functionality in bipolar disorder. Comprehensive Psychiatry, 53(5), 484-489. https://doi.org/10.1016/j.comppsych.2011.08.010

Corrigan, P. W., Larson, J. E., \& Rüsch, N. (2009). Self-stigma and the "why try" effect: Impact on life goals and evidence-based practices. World Psychiatry, 8(2), 75-81.

Davidson, M., Kapara, O., Goldberg, S., Yoffe, R., Noy, S., \& Weiser, M. (2016). A nation-wide study on the percentage of schizophrenia and bipolar disorder patients who earn minimum wage or above. Schizophrenia Bulletin, 42(2), 443-447. https://doi.org/10.1093/schbul/sbv023

Gilbert, A. M., Olino, T. M., Houck, P., Fagiolini, A., Kupfer, D. J., \& Frank, E. (2010). Selfreported cognitive problems predict employment trajectory in patients with bipolar I disorder. Journal of Affective Disorders, 124(3), 324-328.

https://doi.org/10.1016/j.jad.2009.11.012

Gilbert, E., \& Marwaha, S. (2013). Predictors of employment in bipolar disorder: A systematic review. Journal of Affective Disorders, 145(2), 156-164. https://doi.org/10.1016/j.jad.2012.07.009

Giles, D. C., \& Newbold, J. (2013). 'Is this normal?' The role of category predicates in constructing mental illness online. Journal of Computer-Mediated Communication, 18(4), 476-490. https: // doi.org/10.1111/jcc4.12022

Gilkes, M., Perich, T., \& Meade, T. (2018). Predictors of self-stigma in bipolar disorder: Depression, mania, and perceived cognitive function. Stigma and Health. https://psycnet.apa.org/doi/10.1037/sah0000147

Gliddon, E., Barnes, S. J., Murray, G., \& Michalak, E. E. (2017). Online and mobile technologies for self-management in bipolar disorder: A systematic review. Psychiatric Rehabilitation Journal, 40(3), 309-319. https://doi.org/10.1037/prj0000270

Goldberg, S. G. (2012). Becoming the denigrated other: Group relations perspectives on initial reactions to a bipolar disorder diagnosis. Frontiers in Psychology, 3(347). https: / / doi.org/10.3389/fpsyg.2012.00347

Hawke, L. D., Parikh, S. V., \& Michalak, E. E. (2013). Stigma and bipolar disorder: A review of the literature. Journal of Affective Disorders, 150(2), 181-191. https://doi.org/10.1016/j.jad.2013.05.030

Highton-Williamson, E., Priebe, S., \& Giacco, D. (2015). Online social networking in people

The International Journal of Information, Diversity, \& Inclusion, 3(4), 2019

ISSN 2574-3430, jps.library.utoronto.ca/index.php/ijidi/index

DOI: $10.33137 /$ ijidi.v3i4.33011 
with psychosis: A systematic review. International Journal of Social Psychiatry, 61(1), 92-101. https: // doi.org/10.1177\%2F0020764014556392

Horgan, A., \& Sweeney, J. (2010). Young students' use of the Internet for mental health information and support. Journal of Psychiatric and Mental Health Nursing, 17(2), 117123. https://doi.org/10.1111/j.1365-2850.2009.01497.x

Horgan, A., McCarthy, G. \& Sweeney, J. (2013). An evaluation of an online peer support forum for university students with depressive symptoms. Archives of Psychiatric Nursing, 27(2), 84-89. https://doi.org/10.1016/j.apnu.2012.12.005

Karpov, B., Joffe, G., Aaltonen, K., Suvisaari, J., Baryshnikov, I., Näätänen, P., . . . Isometsä, E. (2017). Level of functioning, perceived work ability, and work status among psychiatric patients with major mental disorders. European Psychiatry, 44, 83-89. https://doi.org/10.1016/j.eurpsy.2017.03.010

Kessler, R. C., Akiskal, H. S., Ames, M., Birnbaum, H., Greenberg, P., Hirschfeld, R. M. A., . . . Wang, P. S. (2006). Prevalence and effects of mood disorders on work performance in a nationally representative sample of U.S. workers. The American Journal of Psychiatry, 163(9), 1561-1568. https://psycnet.apa.org/doi/10.1176/appi.ajp.163.9.1561

Lauder, S., Chester, A., Castle, D., Dodd, S., Gliddon, E., Berk, L., . . . Berk, M. (2015). A randomized head to head trial of MoodSwings.net.au: An Internet based self-help program for bipolar disorder. Journal of Affective Disorders, 171, 13-21.

https://doi.org/10.1016/j.jad.2014.08.008

Lawlor, A., \& Kirakowski, J. (2014). Online support groups for mental health: A space for challenging self-stigma or a means of social avoidance? Computers in Human Behavior, 32, 152-161. https://doi.org/10.1016/j.chb.2013.11.015

Levy, B., Tsoy, E., Brodt, M., Petrosyan, K., \& Malloy, M. (2015). Stigma, social anxiety, and illness severity in bipolar disorder: Implications for treatment. Annals of Clinical Psychiatry, 27(1), 55-64.

Marwaha, S., Durrani, A., \& Singh, S. (2013). Employment outcomes in people with bipolar disorder: A systematic review. Acta Psychiatrica Scandinavica, 128(3), 179-193. https://doi.org/10.1111/acps.12087

Michalak, E. E., Yatham, L. N., Maxwell, V., Hale, S., \& Lam, R. W. (2007). The impact of bipolar disorder upon work functioning: A qualitative analysis. Bipolar Disorders, 9(12), 126-143. https://doi.org/10.1111/j.1399-5618.2007.00436.x

Nilsson, K. K., Kugathasan, P., \& Straarup, K. N. (2016). Characteristics, correlates and outcomes of perceived stigmatization in bipolar disorder patients. Journal of Affective Disorders, 194, 196-201. https://doi.org/10.1016/j.jad.2016.01.025

O'Donnell, L. A. (2017). An investigation on predictors of occupational functioning in individuals with bipolar disorder (Doctoral dissertation). Retrieved from https://deepblue.lib.umich.edu/bitstream/handle/2027.42/120711/lao_1.pdf?sequenc e=1\&isAllowed $=y$

The International Journal of Information, Diversity, \& Inclusion, 3(4), 2019

ISSN 2574-3430, jps.library.utoronto.ca/index.php/ijidi/index

DOI: $10.33137 /$ ijidi.v3i4.33011 
O'Donnell, L. A., Deldin, P. J., Grogan-Kaylor, A., McInnis, M. G., Weintraub, J., Ryan, K. A., \& Himle, J. A. (2017). Depression and executive functioning deficits predict poor occupational functioning in a large longitudinal sample with bipolar disorder. Journal of Affective Disorders, 215, 135-142. https://doi.org/10.1016/j.jad.2017.03.015

Poole, R., Simpson, S., \& Smith, D. (2012). Internet-based psychoeducation for bipolar disorder: A qualitative analysis of feasibility, acceptability and impact. BMC Psychiatry, 12(139), 1-10. https://doi.org/10.1186/1471-244X-12-139

Poole, R., Smith, D., \& Simpson, S. (2015). How patients contribute to an online psychoeducation forum for bipolar disorder: A virtual participant observation study. JMIR Mental Health, 2(3), e21. https://doi.org/10.2196/mental.4123

Proudfoot, J., Parker, G., Hyett, M., Manicavasagar, V., Smith, M., Grdovic, S., \& Greenfield, L. (2007). Next generation of self-management education: Web-based bipolar disorder program. Australian and New Zealand Journal of Psychiatry, 41(11), 903-909. https://doi.org/10.1080\%2F00048670701634911

Proudfoot, J., Parker, G., Manicavasagar, V., Hadzi-Pavlovic, D., Whitton, A., Nicholas, J., . . . Burckhardt, R. (2012). Effects of adjunctive peer support on perceptions of illness control and understanding in an online psychoeducation program for bipolar disorder: A randomised controlled trial. Journal of Affective Disorders, 142(1-3), 98-105. https://doi.org/10.1016/j.jad.2012.04.007

Proudfoot, J., Parker, G. B., Benoit, M., Manicavasagar, V., Smith, M., \& Gayed, A. (2009). What happens after diagnosis? Understanding the experiences of patients with newlydiagnosed bipolar disorder. Health Expectations: An International Journal of Public Participation in Health Care \& Health Policy, 12(2), 120-129. https://doi.org/10.1111/j.1369-7625.2009.00541.x

Rains, S. A., Peterson, E. B., \& Wright, K. B. (2015). Communicating social support in computer-mediated contexts: A meta-analytic review of content analyses examining support messages shared online among individuals coping with illness. Communication Monographs, 82(4), 403-430. https://doi.org/10.1080/03637751.2015.1019530

Ryan, K. A., Eisenberg, D., Kim, H. M., Lai, Z., McInnis, M., \& Kilbourne, A. M. (2015). Longitudinal impact of a collaborative care model on employment outcomes in bipolar disorder. Journal of Affective Disorders, 188, 239-242. https://doi.org/10.1016/j.jad.2015.08.052

Saldaña, J. (2014). Coding and analysis strategies. In P. Leavy (Ed.), The Oxford handbook of qualitative research (pp. 581-605). New York, NY: Oxford University Press.

Savolainen, R. (2011). Requesting and providing information in blogs and internet discussion forums. Journal of Documentation, 67(5), 863-886.

https://doi.org/10.1108/00220411111164718

Schotanus-Dijkstra, M., Havinga, P., van Ballegooijen, W., Delfosse, L., Mokkenstorm, J., \& Boon, B. (2014). What do the bereaved by suicide communicate in online support groups? A content analysis. Crisis: The Journal of Crisis Intervention and Suicide

The International Journal of Information, Diversity, \& Inclusion, 3(4), 2019

ISSN 2574-3430, jps.library.utoronto.ca/index.php/ijidi/index

DOI: $10.33137 /$ ijidi.v3i4.33011 
Prevention, 35(1), 27-35. https://doi.org/10.1027/0227-5910/a000225

Sen, A. (2009). The idea of justice. Cambridge, MA: Harvard University Press.

Sillence, E., \& Mo, P. K. H. (2014). Communicating health decisions: An analysis of messages posted to online prostate cancer forums. Health Expectations: An International Journal of Public Participation in Health Care \& Health Policy, 17(2), 244-253. https: / / doi.org/10.1111/j.1369-7625.2011.00745.x

Simon, G. E., Ludman, E. J., Goodale, L. C., Dykstra, D. M., Stone, E., Cutsogeorge, D., . . . Pabiniak, C. (2011). An online recovery plan program: Can peer coaching increase participation? Psychiatric Services, 62(6), 666-669. https: //dx.doi.org/10.1176\%2Fappi.ps.62.6.666

Simon, G. E., Ludman, E. J., Unützer, J., Operskalski, B. H., \& Bauer, M. S. (2008). Severity of mood symptoms and work productivity in people treated for bipolar disorder. Bipolar Disorders, 10(6), 718-725. https://doi.org/10.1111/j.1399-5618.2008.00581.x

Tremblay, C. H. (2011). Workplace accommodations and job success for persons with bipolar disorder. Work: Journal of Prevention, Assessment \& Rehabilitation, 40(4), 479-487. https://doi.org/10.3233/WOR-2011-1259

U.S. Department of Labor. (2015). Need time? The employees guide to the Family Medical Leave Act. Retrieved from https://www.dol.gov/whd/fmla/employeeguide.pdf

Van der Klink, J. J. L., Bültmann, U., Burdorf, A., Schaufeli, W. B., Zijlstra, F. R. H., Abma, F. I., . . . Van der Wilt, G. J. (2016). Sustainable employability - definition, conceptualization, and implications: A perspective based on the capability approach. Scandinavian Journal of Work Environment \& Health, 42(1), 71-79. https://doi.org/10.5271/sjweh.3531

Vayreda, A., \& Antaki, C. (2009). Social support and unsolicited advice in a bipolar disorder online forum. Qualitative Health Research, 19(7), 931-942. https: //doi.org/10.1177\%2F1049732309338952

Venkatapuram, S. (2011). Health justice: An argument from the capabilities approach. Malden, MA: Polity Press.

Venkatapuram, S. (2014). Mental disability, human rights and the capabilities approach: Searching for the foundations. International Review of Psychiatry, 26(4), 408-414. https://doi.org/10.3109/09540261.2014.926867

Venkatapuram, S., Ventriglio, A., \& Bhugra, D. (2015). Capability to be healthy-Implications for prevention. International Journal of Social Psychiatry, 61(5), 518-520. https://doi.org/10.1177\%2F0020764015588000

World Health Organization. (2011, December 1). Global burden of mental disorders and the need for a comprehensive, coordinated response from health and social sectors at the country level (EB 130/9). Retrieved from http://apps.who.int/gb/ebwha/pdf_files/eb130/b130_9-en.pdf

The International Journal of Information, Diversity, \& Inclusion, 3(4), 2019

ISSN 2574-3430, jps. library.utoronto.ca/index.php/ijidi/index

DOI: $10.33137 /$ ijidi.v3i4.33011 
Yao, T., Zheng, Q., \& Fan, X. (2015). The impact of online social support on patients' quality of life and the moderating role of social exclusion. Journal of Service Research, 18(3), 369-383. https://doi.org/10.1177\%2F1094670515583271

Susan Rathbun-Grubb (srathbun@mailbox.sc.edu) is an Associate Professor at the School of Library and Information Science at the University of South Carolina. Her research centers on the intersection of education, training, and careers in library and information science (LIS). She is particularly interested in career progression across the life course, job satisfaction, and the evaluation of pedagogical strategies in LIS education. Dr. Rathbun-Grubb teaches in the areas of information organization and reference services, and she has worked in academic, public, and school libraries, as well as in the health information technology industry. 